\title{
Shiga toxin producing Escherichia coli: identification of non-0157:H7-Super-Shedding cows and related risk factors
}

\author{
Andrea Menrath ${ }^{1 *}$, Lothar H Wieler ${ }^{2}$, Katrin Heidemanns ${ }^{2}$, Torsten Semmler ${ }^{2}$, Angelika Fruth ${ }^{3}$, Nicole Kemper ${ }^{1}$
}

\begin{abstract}
Background: Shiga toxin producing Escherichia coli (STEC) are an important cause of human gastro-enteritis and extraintestinal sequelae, with ruminants, especially cattle, as the major source of infection and reservoir. In this study, the fecal STEC shedding of 133 dairy cows was analyzed over a period of twelve months by monthly sampling with the aim to investigate shedding patterns and risk factors.

Results: Overall, 24.7\% (in total 407) of 1,646 fecal samples were tested positive for stx by PCR with inner-herd prevalences on the different farms of $11.1 \%$ to $32.3 \%$. At individual levels, cows were stx-positive on zero to eight consecutive samplings. According to a strictly longitudinal definition of Super-Shedding, in the present study 14 cows were identified as Super-Shedders of non-0157 serotypes.

Significant risk factors for the shedding of STEC were the month of sampling, the number of lactations and days in lactation, the nutritional condition, the somatic cell count and the content of protein in milk. Most notably, the presence of STEC Super-Shedding cows in the herd was a significant risk factor, revealing that STEC Super-Shedding is not restricted to STEC O157:H7 alone.
\end{abstract}

Conclusions: These data have implications for possible interventions, as removing single non-O157:H7 STEC SuperShedding cattle from farms would significantly reduce STEC burden.

\section{Background}

Shiga toxin producing Escherichia coli (STEC) are an emerging issue for veterinary public health. Their zoonotic relevance is related to the severity of caused diseases and the low dose of ten to 100 bacteria [1]. The highly cytotoxic Shiga toxin combined with other virulence factors causes gastroenteritis and severe sequelae in children with a low, but steady incidence. Most research to date has concentrated on the STEC-serovar O157:H7, but in Germany and other European countries human infections by non-O157:H7 serovars have also been frequently assessed [2-5]. The only consistent difference of these STEC-serovars to apathogenic Escherichia coli $(E$. coli) is the possession of Shiga toxin (stx) genes. Potentially pathogenic STEC for humans, causing hemorrhagic colitis and mostly possessing the genes for stx $x_{2}, E H E C-h l y_{A}$ and eae, encoding intimin, a factor of

\footnotetext{
* Correspondence: amenrath@tierzucht.uni-kiel.de

Institute of Animal Breeding and Husbandry, Christian-Albrechts-University, Hermann-Rodewald-Str. 6, 24118 Kiel, Germany
}

adherence, are so-called enterohemorrhagic E. coli (EHEC), but also other STEC can induce serious disease in humans $[2,3,6]$. Ruminants, and especially cattle, are considered as a natural reservoir of STEC. Extended risks originate in domesticated cattle kept in close contact to humans. Furthermore, cattle-derived foods can be contaminated and represent an important source of infection as well $[7,8]$. Bovine carriers of STEC show no sign of clinical disease whilst shedding this pathogen.

Risk factors for fecal shedding by dairy cattle are varied, including different factors of management such as hygiene, the kind of diet, husbandry and changes in housing or structure of the herd [9-11]. Moreover, at least for the serovar O157:H7, the individual characteristics of each cow also seem to have an influence [12]. Based on data from Synge et al., Matthews et al. formed a model simulating the excretion- and transmissiondynamics of STEC O157:H7 in a cattle herd [13-15]. The model fit best to the real data if a small proportion of cows had a 50-fold higher excretion of STEC O157: 
H7 compared to the other animals $[14,15]$. Up to $80.0 \%$ of the transmissions of STEC O157:H7 to uninfected cows originated in $20.0 \%$ of the most infectious cows [14]. These high-level STEC shedding cows were defined as Super-Shedders [12,15]. A high-level excretion of STEC as shown by these Super-Shedders is associated with the colonization of the recto-anal junction of their gastrointestinal tract $[12,15,16]$.

According to the definition of Chase-Topping et al., all cows that shed at least $10^{4} \mathrm{cfu}$ (colony forming units) STEC O157:H7 per gram feces were characterized as Super-Shedders [12]. In this definition, the longitudinal component of Super-Shedding was totally neglected. However, the concentration of STEC O157:H7 was shown to be associated with the duration of shedding [17]. Hence, in the present study, as in the investigations of Lim et al. and Carlson et al., the longitudinal part of the definition was used $[18,19]$. In both studies, cows were defined as Super-Shedders, or alternatively as Persistent-Shedders, if they shed STEC O157:H7 for more than three consecutive months. In this study, the definition of a Super-Shedder was extended as follows: cows were classified as Super-Shedders if at least half of their samples and equal or more than four consecutive samples were stx-positive.

The aim of this study was to investigate risk factors in milk production for STEC shedding in general by dairy cattle. Furthermore, the occurrence of possible SuperShedding cows, shedding not only STEC O157:H7 but also other STEC-serovars, was examined by longitudinal and qualitative sampling over the period of twelve months.

\section{Results}

In $24.7 \%$ (407) of all samples, stx genes were detected by the screening PCR. Within the herds, the mean stx prevalence varied between $11.1 \%$ and $32.3 \%$.

Of all cows sampled for more than six months ( $\mathrm{n}=$ 140 ), only $12.9 \%$ (18 cows) were detected as constantly st $x$-negative. Most of the animals excreted stx at least once (45.5\%, 55 cows), and $17.1 \%$ (24 cows) were classed as $s t x$-positive in more than $50 \%$ of their samples. In $40.7 \%$ (57 cows), the maximal duration of st $x$ shedding was one sampling, whereas 29 of these cows were identified as intermittent shedders. They were detected in one to three additional but not consecutive samplings. For $32.9 \%$ (46 cows) that shed stx in two to three consecutive samplings, these samplings in most of the cases (35 cows) were followed by other short periods of stx shedding. Seventeen cows (12.1\%) were determined to be stx-positive in the screening PCR in four or five consecutive samplings. In total, twelve of these cows had additional periods of shedding intermittently or for short periods. Two cows $(1.6 \%)$ were characterized by a great number of consecutive stx-positive samplings: one cow was determined to be stx-positive in seven consecutive samplings, the other even over eight consecutive samplings (Table 1 ). In total, 14 cows (10.0\%) were identified as Super-Shedders according to the definition with positive stx-detection in the screening PCR on at least four consecutive samplings and in equal to or more than half of their samples. In the sampling period, STEC-colonies were isolated resulting in 1,105 STECisolates from 144 of the 407 stx-positive fecal samples. Dominating combinations of virulence genes were $s t x_{2}$ and $E H E C-h l y_{A}\left(434\right.$ isolates, 39.3\%), and $s t x_{1}, s t x_{2}$ and EHEC-hly ${ }_{A}$ (311 isolates, 28.1\%) (Table 2).

From 14 Super-Shedding animals, 380 isolates were identified. From these isolates, 61 STEC-isolates of six Super-Shedders were selected for serotyping based on their virulence pattern, the date of sampling and the cow of origin. To represent each of the four farms with SuperShedding cows, STEC-isolates from one Super Shedder per farm were chosen. Assuming that on one farm different serovars might be present, STEC-isolates from two additional cows on one of the farms were serotyped. The characterized STEC-isolates belonged to 24 sorbitol-fermenting non-O157:H7 STEC serovars (Table 3). The two

\begin{tabular}{|c|c|c|}
\hline $\begin{array}{l}\text { consecutive stx-positive samples } \\
\text { (monthly sampling) }\end{array}$ & no. of cows & $\%$ of cows \\
\hline 0 & 18 & $12.9 \%$ \\
\hline 1 & 57 & $40.7 \%$ \\
\hline $2-3$ & 46 & $32.9 \%$ \\
\hline $4-5$ & 17 & $12.1 \%$ \\
\hline $7-8$ & 2 & $1.6 \%$ \\
\hline
\end{tabular}

$\%$ : percentage

Table 2 Prevalences of virulence factors from isolated STEC ( $n=1,105$ isolates)

\begin{tabular}{cccccc}
\hline stx $_{\mathbf{1}}$ & stx $_{\mathbf{2}}$ & eae & EHEC-hly & no. (\%) of pos. Isolates (total: 1,105) \\
\hline- & + & - & + & 434 & $(39.3 \%)$ \\
+ & + & - & + & 311 & $(28.1 \%)$ \\
- & + & - & - & 145 & $(13.1 \%)$ \\
+ & + & - & - & 56 & $(5.1 \%)$ \\
- & + & + & + & 43 & $(3.9 \%)$ \\
+ & - & - & - & 35 & $(3.2 \%)$ \\
+ & - & - & + & 33 & $(3.0 \%)$ \\
+ & - & + & + & 24 & $(2.2 \%)$ \\
+ & + & + & + & 17 & $(1.5 \%)$ \\
- & + & + & - & 4 & $(0.4 \%)$ \\
+ & + & + & - & 2 & $(0.2 \%)$ \\
+ & - & + & - & 1 & $(0.1 \%)$ \\
\hline
\end{tabular}

pos.: positive

$\%$ : percentage 
Table 3 Serotypes and virulence patterns of tested STEC-isolates $(n=61)$ from six selected Super-Shedders

\begin{tabular}{|c|c|c|c|c|c|}
\hline \multirow[b]{2}{*}{ serovars } & \multirow[b]{2}{*}{ no. of isolates } & \multicolumn{3}{|c|}{ virulence patterns } & \multirow[b]{2}{*}{$\begin{array}{l}\text { until now isolated according } \\
\text { to MicroBioNet [43] }\end{array}$} \\
\hline & & stx $_{2}+$, EHEC- $_{-h_{l y A}+}$ & $s t x_{1}+$, stx $_{2}+$, EHEC-hly $A_{A}+$ & other & \\
\hline O113:NM & 16 & 13 & 2 & $1\left(s t x_{2}+\right)$ & cattle, human (D) \\
\hline $\mathrm{O} 22: \mathrm{H} 8$ & 10 & 4 & 5 & $1\left(s t x_{1}+, E^{\prime} C_{-h l y A}+\right)$ & cattle, human (D, HUS) \\
\hline Ont:H25 & 7 & 5 & 1 & $1\left(s t x_{2}+, e a e+\right)$ & cattle, human (D) \\
\hline O130:H11 & 6 & 2 & 4 & & cattle \\
\hline O8:H19 & 2 & 2 & & & cattle, human (D, HUS) \\
\hline O18:H8 & 2 & 1 & & $1\left(s t x_{1}+, E H E C_{-h l y A}+\right)$ & - \\
\hline $\mathrm{O} 113: \mathrm{H} 21$ & 2 & 2 & & & cattle, human (D, HUS, TTP) \\
\hline O138:H34 & 2 & 1 & & $1\left(s t x_{2}+\right)$ & cattle \\
\hline $\mathrm{O} 5: \mathrm{H7}$ & 1 & & 1 & & cattle \\
\hline $\mathrm{O} 8 \mathrm{H} 21$ & 1 & & & $1\left(s t x_{1}+\right)$ & human (HUS) \\
\hline O28:H31 & 1 & 1 & & & - \\
\hline O80:H45 & 1 & 1 & & & - \\
\hline O91:H7 & 1 & 1 & & & cattle \\
\hline O150:H8 & 1 & & 1 & & cattle \\
\hline Ont:H7 & 1 & & & $1\left(s t x_{2}+\right)$ & cattle, human (D) \\
\hline Ont:H19 & 1 & 1 & & & cattle, human (D) \\
\hline Ont:H21 & 1 & 1 & & & cattle, human (D) \\
\hline Ont:H39 & 1 & 1 & & & - \\
\hline Ont:H42 & 1 & 1 & & & cattle \\
\hline Orough:NM & 1 & 1 & & & cattle, human (D, HUS) \\
\hline Orough:H2 & 1 & & & $1\left(\text { stx }_{1}+\text {, eaet, } \text { EHEC-hlyA }_{-}+\right)^{1}$ & cattle, human \\
\hline Orough:Hnt & 1 & 1 & & & cattle, human (D) \\
\hline
\end{tabular}

cattle: healthy cattle; human: healthy human; human (D): human case with diarrhea; human (TTP): human case with thrombotic-thrombocytopenic purpura; human (HUS): human case with hemolytic-uremic syndrome

1: potential EHEC: STEC with virulence pattern stx ${ }_{2}+$, EHEC-hly ${ }_{A}+$ and eae+

-: no isolation recorded in MicroBioNet [43]

most predominant serovars were serovar O113:NM (16 isolates, 26.2\%) and $\mathrm{O} 22: \mathrm{H} 8$ (10 isolates, $16.4 \%$ ), the most frequent virulence patterns of these STEC were $s t x_{2}$ and $E H E C-h l y_{A}$ (39 isolates, 63.9\%).

In one cow, the serovar O22:H8 was isolated on each sampling date from July to November. In September, this cow began to shed additionally the serovar O113: $\mathrm{NM}$ for the next five consecutive samplings until January. On the same farm, another cow shed the serovar O113:NM over nearly the same period from November to December.

Several risk factors were identified in this study as significant influences on the detection of stx in bovine feces: days in milk (DIM) and the number of lactations, the somatic cell count, the content of protein and urea in milk and the nutritional condition. Furthermore, the presence of Super-Shedding cows in the herd and the month of sampling represented significant risk factors. Depending on the DIM class, dry cows, and cows with 50 to 150 days as well as cows with more than 350 days in milk showed a significantly higher risk or a higher tendency to shed STEC (Table 4). First-calving cows, cows with a somatic cell count lower than 100,000 cells/ $\mathrm{ml}$ milk, a protein content in milk higher than $3.0 \%$, respectively a body condition score higher than 3.50 had a significantly or tendentially increased risk to be identified as STEC-shedders by the screening PCR, whereas cows with an urea content lower than $150 \mathrm{mg} / \mathrm{L}$ milk had a decreased risk (Table 4).

Additionally, a cow kept in a herd with Super-Shedders had a significant, more than two-fold risk of being positive in the $s t x$-detection by PCR compared to a cow in a herd with no Super-Shedder (Table 4).

The stx prevalence was highest in the late summer months (August, September, and October) with 27.9\%, $28.8 \%$ and $35.0 \%$ in contrast to the spring months with lower prevalence (February: 20.5\%, March: 17.6\%, April: $16.3 \%)$. In consequence, cows showed a significant higher risk for detection as stx-positive in summer, autumn and winter compared to that in spring. Furthermore, cows had a significantly higher risk in autumn for shedding stx than in winter (Table 5).

\section{Discussion}

Many studies have examined the epidemiology of STEC O157:H7 in cattle populations, but there have been only 
Table 4 Significant risk factors for shedding of STEC by dairy cattle

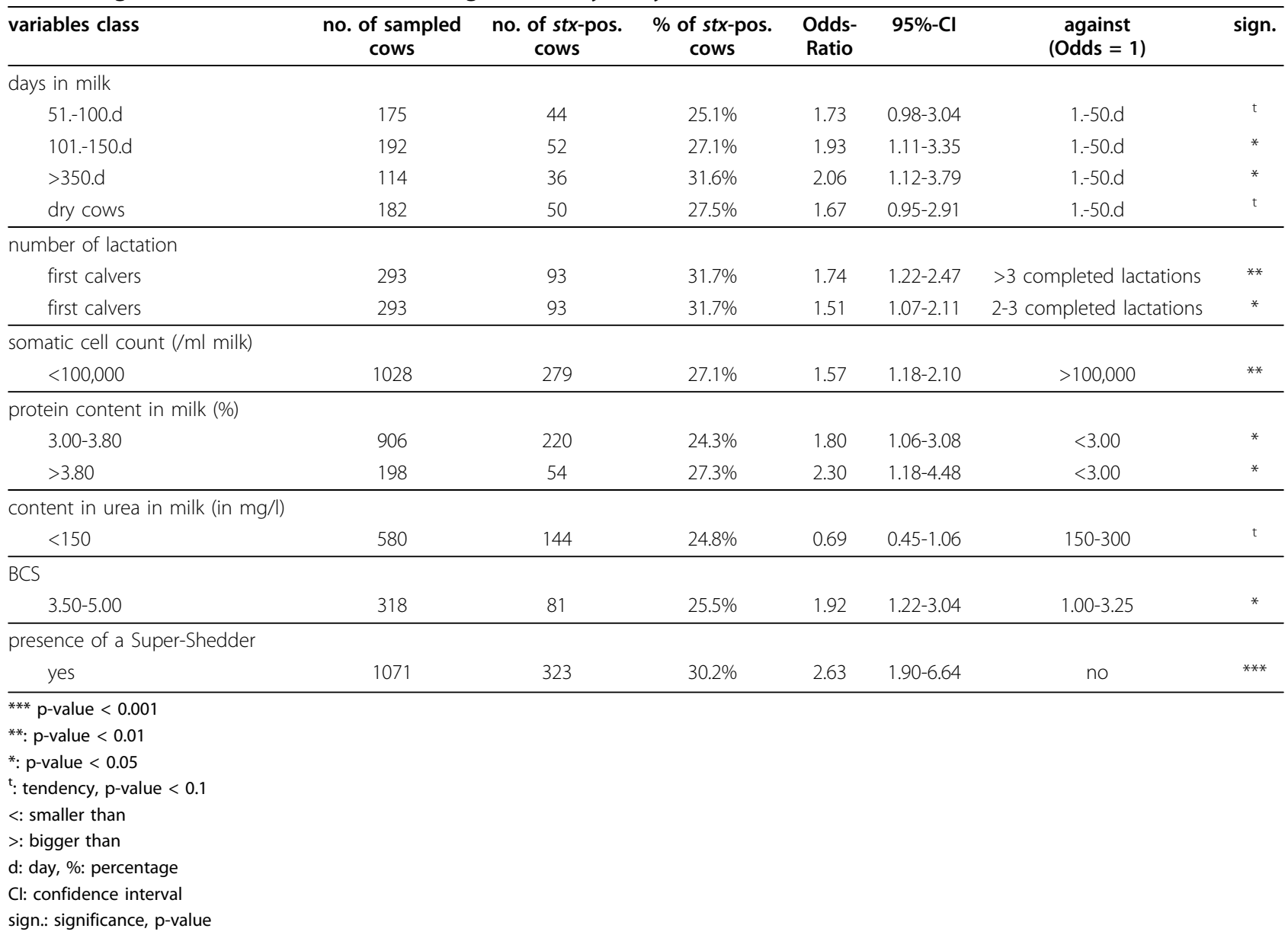

BCS: body condition score according to Edmonson et al. [51]

Table 5 Seasonality of stx-detection in feces of examined cattle expressed in Odds Ratios

\begin{tabular}{lcccc}
\hline & \multicolumn{4}{c}{ Odds $=\mathbf{1}$} \\
\cline { 2 - 5 } seasons & spring & summer & autumn & winter \\
\hline spring & $X$ & $0.61^{*}$ & $0.43^{* * *}$ & $0.63^{*}$ \\
summer & $1.64^{*}$ & $X$ & $0.70^{t}$ & 1.02 \\
autumn & $2.35^{* * *}$ & $1.43^{\mathrm{t}}$ & $X$ & $1.47^{*}$ \\
winter & $1.60^{*}$ & 0.98 & $0.68^{*}$ & $X$ \\
\hline
\end{tabular}

spring: February, March, April

summer: May, June, July

autumn: August, September, October

winter: November, December, January

*** $p$-value $<0.001$

*: p-value $<0.05$

t: tendency, p-value $<0.1$

a few investigations into the relevance and the transferability of these results to other serovars, for instance O26, O91 or O113. These serovars have been detected in cattle herds and are also relevant for human diseases $[2,3,20]$. Therefore, this study considered STEC in general, not only O157:H7.
Following an evaluation of the shedding patterns of all investigated cows, the strict definition of Super-Shedders with at least four consecutive $s t x$-positive samples in the screening PCR and at least half of their samples deemed stx-positive was necessary to distinguish intermittentshedding and persistent-shedding cows. A strictly longitudinal definition of a Super-Shedder as in the present study was also used in the investigations of Lim et al. and Carlson et al. $[18,19]$. Carlson et al. reasoned this definition by findings of Woerner et al. that the persistence of shedding of $\mathrm{O} 157: \mathrm{H7}$ is much more important than the STEC count in the feces, as suggested by Chase-Topping et al. in their definition of a Super-Shedder $[12,19,21]$.

Due to the methodological approach which included a step of high dilution $\left(10^{-5}-10^{-6}\right)$ to plate the bacteria for the colony-hybridization, an efficient isolation of STEC gave a hint of high numbers of STEC in the fecal sample. The isolation of STEC in this study mainly was possible in the samples of Super-Shedders, which is congruent with the results mentioned by Chase-Topping 
et al. who defined Super-Shedders basically about the number of shed STEC [12].

To our knowledge, the study presented here is the first showing Super-Shedding of serovars other than O157:H7 by Super-Shedder dairy cattle.

Compared to the study of Low et al. with $3.9 \%$ of all cows identified as Super-Shedders for the serovar O157:H7, the proportion of analyzed Super-Shedders for non-O157:H7 serovars in all investigated herds in this study was high with $10.0 \%$ (14 cows) [22]. This is possibly due to the higher colonization of cattle with non-0157:H7-serovars [23,24]. In general, a high proportion of Super-Shedders is associated with a high proportion of low-level and intermittent shedders due to the higher possibility of transmission [22,25]. As previously described for STEC strains in cattle, most of the isolated strains do not possess the eae gene $[23,26]$. However, the mechanisms of adherence for bovine non-O157:H7 STEC-isolates are not restricted to eae but also include local or diffuse adherence on HEp2cells [27]. Further virulence factors of adherence for non-O157:H7 STEC, also associated with human diseases, could comprise Saa (an autoagglutinating adhesion), Iha (adherence-conferring protein similar to Vibrio cholerae $\operatorname{IrgA}$ ), Efa1 (E. coli factor for adherence) and LPF (long polar fimbriae; closely related to LPF of Salmonella enterica serovar Typhimurium) [28-32]. Concerning Efa1, Stevens et al. proved in in vivo experiments the relevance of this virulence factor for the colonization of intestinal mucosa in cattle [29]. As we currently do not know whether Super-Shedding of non-O157:H7 STEC is also caused by enhanced colonization of the terminal rectum, as it has been shown for O157:H7 colonization, future studies clearly should address these questions [33].

Congruent to other literature, a STEC prevalence of $24.7 \%$ was detected in healthy dairy cows in Northern Germany in this study $[23,26]$. In other studies in Germany, values from $18.0 \%$ up to $86 \%$ were assessed [23,34-36]. In the other parts of Europe, the prevalence was supposed to be slightly lower with percentages of $11.0 \%$ to $21.0 \%$ [37]. Differences in the obtained prevalence can be related to different methods of detection on the one hand and the sampling method and the sample size on the other hand. The methodology used in the present study and also in the study by Geue et al. with an enrichment step before the PCR and the colony-hybridization resulted in the hitherto highest prevalence of STEC in beef cattle and heifers in Germany [23]. The most sensitive sampling method, at least for STEC O157:H7, seemed to be the rectal swab $[38,39]$. This is probably due to the colonisation of the rectoanal junction of the intestinal mucosa, which is directly sampled by the swab $[16,22]$.
Only 18 animals (12.9\%) of 140 sampled cows were $s t x$-negative over the whole period of sampling. Most of the cows were defined as intermittent shedders; they were $s t x$-positive in the PCR for short periods of consecutive samplings or for one sampling, but did not reach the number of consecutive stx-positive samplings necessary to fulfill the definition of a Super-Shedder.

With regard to the virulence gene patterns, the assessed dominance of $s t x_{2}$ and $s t x_{1}+s t x_{2}$-positive strains in cattle in the present study is in accordance with other authors $[23,26]$. This high proportion of $s t x_{2}$, known as the most virulent Shiga toxin for humans, in bovine STEC strains poses an important risk for humans in contact with cattle and cattle-derived foods. This holds especially true because several cases of STEC infections in humans have been associated with STEC strains without the eae gene, but with $s t x_{2}$ and other factors for adhesion [1,30,40-42].

Based on the technical and methodological efforts of serotyping, only 61 isolates originating in the SuperShedding cows were examined. These serovars belonged to 24 non-O157:H7 STEC-serovars, partly with previous references of description in healthy cattle but also in healthy and diseased human [43]. This diversity of serovars is typical for cattle; Blanco et al. isolated in 328 cattle 66 STEC that belong to 25 serovars [44]. Three of the most frequent serogroups in the present study were also identified in the investigation of Blanco et al. [44]. Eight of the serovars isolated in the present study have already been associated with diseases in humans [43]. Especially the serovars O8:H19, O8:H21, O22:H8, O113:H21 and Orough:NM were also detected in diseased humans with hemolytic-uremic syndrome (HUS) and thromboticthrombocytopenic purpura (TTP), seven other isolated serovars (see Table 3) were isolated in cases of humans with diarrhea [43]. The most predominant serovars O113:NM and O22:H8 induced diarrhea respectively diarrhea and hemolytic-uremic syndrome (HUS) in some cases in humans [43]. The serovar Orough: $\mathrm{H} 2$ was not associated with the induction of severe human disease but was characterized by the possession of $s t x_{2}, E H E C$ $h y_{A}$ and eae genes, which is the typical virulence patterns for the human pathogen EHEC [43].

In the present study, one single cow hosted two to four different serovars. However, this number is limited by the number of colonies taken from the plate. In the study of Blanco et al., up to three different serovars were isolated by some cows [44].

The serotyping of the small proportion of all isolates was sufficient to confirm the hypothesis of Super-Shedders of non-O157:H7 STEC by at least two cows shedding continuously O113:NM and 022:H8. This indicates that also non-O157:H7 serovars are able to colonize the bovine intestinal mucosa, resulting in persistent Super- 
Shedding. Further studies under defined experimental conditions are needed to investigate the precise colonization and shedding in detail. Regarding the other risk factors, the seasonality for the shedding strains serogroup O157 showed highest prevalence in summer, those for STEC in general a prevalence peak in autumn $[45,46]$. In accordance with both studies, the highest prevalences in this study were also detected in the late summer months. Thus, saisonality is clearly associated with STEC shedding, regardless of which serotype is tested for.

The higher risk for heifers and for cows with 50 to 150 days in milk can be explained by the metabolic and emotional stress of these animals and actually was shown for serovar O157:H7 [25,47]. The relevance of age for the occurrence of pathogenic $E$. coli has already been presented by Wieler et al. [48]. Regarding O157: $\mathrm{H} 7$, only few studies have dealt with the connection of milk content and the shedding of this serovar [11]. These authors clearly showed the impact of milk content, probably related to diet, health and stress, on the shedding of non-O157:H7 STEC as well. Moreover, the presence of a Super-Shedder in the herd as a persistent source of infection was shown to be a risk factor for the shedding of serogroup O157 and was confirmed for non-O157:H7 STEC [12].

\section{Conclusion}

This study confirms the importance of seasonality and Super-Shedders as a major cause of non-O157:H7 STEC shedding in cattle farms. Super-Shedders maintain and aggravate the infectious cycle of STEC in the herd; therefore, interventions at individual animal level might serve as the basis for effective pathogen control. Pathogen virulence profiles, common in human isolates, are frequently found in bovine STEC, corroborating the important reservoir function of cattle as potential human health risks. Risk factors for the excretion of STEC have been examined before; however the situation remains rather complex, and main influencing factors varied due to study design and animal premises analyzed. The importance of Super-Shedders for the intra herd epidemiology of non-O157:H7 STEC should be proven by intervention strategies. Future research approaches should concentrate on the facilitated identification of Super-Shedders and the development of potent vaccines or treatments. These strategies represent the key to an effective interruption of STEC-infection cycles.

\section{Methods}

\section{Animal selection and sample collection}

The study was conducted on six dairy farms in Schleswig-Holstein/Germany in the period of $02 / 2007$ until $01 / 2008$ over twelve months. These farms were chosen out of ten farms that had participated in a previous investigation on the evaluation of the health status of dairy cows in correlation with farm type, diet and herd management [49]. The design of the study was longitudinal with the intent to follow the fecal excretion patterns of STEC of selected cows. Therefore, the distribution of cows in different numbers of lactation was analyzed and, according to this distribution, the cows for sampling were randomly selected on each farm. The necessary number of sampled cows was calculated with the formula suggested by Cannon and Roe, with a limit of significance of $90.0 \%$ and an estimated prevalence of $50.0 \%$ [50].

The analysis of certain risk factors for the individual animal and for the herd was performed with additional information about herd management, health status and body condition scores [51], which were evaluated on each sampling day. Moreover, data on the amount and content of milk, the number of passed lactations and the days in milk were provided by the regional organization for animal recording ('Landeskontrollverband Schleswig-Holstein'). A number of 1,646 fecal samples were examined, originating from 182 cows. However, 133 of these cows on the six farms were sampled monthly during the whole period of sampling. Animals sampled at least six consecutive times, 140 cows, were considered in the descriptive longitudinal analysis of shedding.

Fecal samples of approximately $20 \mathrm{~g}$ were taken by fecal grab with disposal gloves, if possible. Dry cows, kept on pastures in summer, were observed und fresh feces from the pasture were taken immediately after shedding.

\section{Bacterial culture and identification of STEC}

All samples were examined in the laboratory within eight hours of collection. The fecal samples were mixed manually; afterwards a swab was plunged three to five times in the sample. The swab was agitated in a twomilliliter phosphate buffered saline-solution for one minute. Fifty micro liters of this dilution were added to three milliliters Luria-Bertani (LB)-bouillon and incubated over night at $150 \mathrm{rpm}$ by $37^{\circ} \mathrm{C}$. Following to this enrichment step, DNA of each sample was prepared by boiling for $20 \mathrm{~min}$, and screened with the primers MK1 and MK2 according to the PCR published by Karch and Meyer [52]. Fifty micro liters of the Shiga toxin genepositive samples and $100 \mu \mathrm{l}$ of a $1 \times 10^{-5}$-fold dilution and $100 \mu \mathrm{l}$ of a $1 \times 10^{-6}$-fold dilution were plated on LB-agar-plates. After $18 \mathrm{~h}$ of incubation, plates with equally distributed single colonies in a number of 100 to 500 were examined by colony-hybridization using the DIG-Kit (Roche Diagnostics GmbH, Mannheim/Germany) following the manufacturers protocol to isolate 
STEC. The probe was synthesized by PCR-labeling with the PCR-DIG labeling set (Roche Diagnostics) and the primers MK1 and MK2 mentioned above [52]. Up to 20 identified STEC-colonies per sample were isolated and characterized by PCR for the virulence factors $s t x_{1}, s t x_{2}$, eae (intimin) and EHEC-hly ${ }_{A}\left(\right.$ EHEC-hemolysin $\left._{\mathrm{A}}\right)$ with primers described before [53-56]. Furthermore, representing the Super-Shedders on farm level three SuperShedding cows of three farms with Super-Shedders were selected. On another farm, three Super-Shedders were chosen to indicate present serotypes on herd level. From of all 278 STEC isolated from these six Super-Shedders, groups were formed, classified by virulence patterns, sampling date and sampled animal, followed by a random selection of one STEC-isolate per group. This resulted in 61 STEC-isolates which were tested serologically by the Robert Koch Institute following the protocol of Ørskov and Ørskov [57]. In this study, cows were defined as Super-Shedders if at least half of their samples and equal or more than four consecutive samplings were classed as stx-positive.

\section{Data analysis}

The data were statistically analyzed using the program 'Excel' (Windows XP, Microsoft Office Excel 2003) and the procedure 'logistic' in 'SAS' (SAS ${ }^{\circ} 9.1$, SAS Institute Inc, Cary, NC, USA) calculating Odds Ratios (OR). Comparisons with $\mathrm{p}$-values $<0.05$ were considered as statistically significant; p-values between 0.05 and 0.10 were indicated as statistical tendency.

The selected model included the following variables: the results of the screening PCR according to Karch and Meyer in the specification of zero - corresponding to no stx detected in the feces of the sampled cow - and one corresponding to stx detected in the feces of the sampled cow - were used as dependent variables [52]. As independent variables, the month of sampling ( 1 for January, 2 for February, 3 for March and so on), and the farm and the number of lactation were considered. All sampled cows were categorized in three classes by their number of lactation: the first class included the first calving cows, the second class the cows in the second and third lactation, and the third class all cows that completed more than three lactations. Another independent variable was the number of days in milk (DIM), classified in classes of 50 days (DIM-Class $1=$ cows in $1^{\text {st }}$ to $50^{\text {th }}$ day of lactation, DIM-Class $2=$ cows in $51^{\text {st }}$ to $100^{\text {th }}$ day of lactation and so on; DIM-class $8=$ all cows in lactation for more than 350 days, DIM-class $9=$ all dry cows). Furthermore, the model included the presence of Super-Shedding cows in the herd. Cows with at least half of their samples and at least four consecutive st $x$-positive samples in the screening PCR were defined as Super-Shedding cows using the strictly longitudinal definition. Because of the limited sample size, each additional variable such as milk yield, milk contents and body condition score (BCS) was added separately to the model in single steps and the respective odds ratios were estimated.

\section{Acknowledgements}

This work was supported by the H.W. Schaumann-Foundation and the BMBF-network "FBI-Zoo" (Food-Borne Zoonotic Infections of Humans, grant no. $01 \mathrm{KI07120).}$

\section{Author details}

'Institute of Animal Breeding and Husbandry, Christian-Albrechts-University, Hermann-Rodewald-Str. 6, 24118 Kiel, Germany. ${ }^{2}$ Institute of Microbiology and Epizootics, Veterinary Faculty, Free University, Philippstr. 13, 10115 Berlin, Germany. ${ }^{3}$ Robert Koch Institute, National Reference Centre of Salmonella and Other Enteric Pathogens, Burgstraße 37, 38855 Wernigerode, Germany.

\section{Authors' contributions}

AM carried out all samplings and the bacteriological analyses and draft the manuscript. LW made substantial contributions to the interpretation of the results. $\mathrm{KH}$ and TS provided support in the validation of results. LW, KH and TS critically revised the manuscript. AF managed the serotyping of the STECisolates. NK designed and coordinated the study and was involved in drafting the manuscript.

All authors read and approved the final manuscript.

\section{Competing interests}

The authors declare that they have no competing interests.

Received: 10 May 2010 Accepted: 9 July 2010 Published: 9 July 2010

\section{References}

1. Karch H, Tarr PI, Bielaszewska M: Enterohaemorrhagic Escherichia coli in human medicine. Int J Med Microbiol 2005, 295:405-418.

2. Bielaszewska M, Köck R, Friedrich A, von Eiff C, Zimmerhackl L, Karch H, Mellmann A: Shiga toxin-mediated hemolytic uremic syndrome: time to change the diagnostic paradigm? PLoS One 2007, 2.

3. Bielaszewska M, Zhang WL, Mellmann A, Karch H: Enterohaemorrhagic Escherichia coli O26: $\mathrm{H11/H}$-: A human pathogen in emergence. Berl Munch Tierarztl Wochenschr 2007, 120:279-287.

4. Bockemühl J, Karch H, Tsch228; pe H: Zur Situation der Infektionen des Menschen durch enteroh228;morrhagische Escherichia coli (EHEC) in Deutschland 1997. Bundesgesundheitsblatt 1998, 41:2-5.

5. Karch H, Mellmann A, Bielaszewska M: Epidemiology and pathogenesis of enterohaemorrhagic Escherichia coli. Berl Munch Tierarztl Wochenschr 2009, 122:417-424.

6. Levine MM: Escherichia coli that cause diarrhea - enterotoxigenic, enteropathogenic, enteroinvasive, enterohemorrhagic, and enteroadherent. Am J Infect Dis 1987, 155:377-389.

7. Vogt RL, Dippold L: Escherichia coli 0157:H7 outbreak associated with consumption of ground beef, June-July 2002. Public Health Rep 2005, 120:174-178.

8. Werber D, Behnke SC, Fruth A, Merle R, Menzler S, Glaser S, Kreienbrock L, Prager R, Tschape H, Roggentin $P$, et al: Shiga toxin-producing Escherichia coli infection in Germany: different risk factors for different age groups. Am J Epidemiol 2007, 165:425-434.

9. Callaway TR, Elder RO, Keen JE, Anderson RC, Nisbet DJ: Forage feeding to reduce preharvest Escherichia coli populations in cattle, a review. J Dairy Sci 2003, 86:852-860.

10. Ellis-Iversen J, Smith RP, Snow LC, Watson E, Millar MF, Pritchard GC, Sayers AR, Cook AJC, Evans SJ, Paiba GA: Identification of management risk factors for VTEC 0157 in young-stock in England and Wales. Prev Vet Med 2007, 82:29-41.

11. Kuhnert P, Dubosson CR, Roesch M, Homfeld E, Doherr MG, Blum JW: Prevalence and risk-factor analysis of Shiga toxigenic Escherichia coli in faecal samples of organically and conventionally farmed dairy cattle. Vet Microbiol 2005, 109:37-45. 
12. Chase-Topping M, Gally D, Low C, Matthews L, Woolhouse M: Supershedding and the link between human infection and livestock carriage of Escherichia coli 0157. Nat Rev Microbiol 2008, 6:904-912.

13. Synge BA, Chase-Topping ME, Hopkins GF, McKendrick IJ, ThomsonCarter F, Gray D, Rusbridge SM, Munro FI, Foster G, Gunn GJ: Factors influencing the shedding of verocytotoxin-producing Escherichia coli 0157 by beef suckler cows. Epidemiol Infect 2003, 130:301-312.

14. Matthews L, Low JC, Gally DL, Pearce MC, Mellor DJ, Heesterbeek JAP, Chase-Topping M, Naylor SW, Shaw DJ, Reid SWJ, et al: Heterogeneous shedding of Escherichia coli $\mathrm{O} 157$ in cattle and its implications for control. Proc Natl Acad Sci USA 2006, 103:547-552.

15. Matthews L, McKendrick IJ, Ternent H, Gunn GJ, Synge B, Woolhouse MEJ: Super-shedding cattle and the transmission dynamics of Escherichia coli 0157. Epidemiol Infect 2006, 134:131-142.

16. Naylor SW, Low JC, Besser TE, Mahajan A, Gunn GJ, Pearce MC, McKendrick IJ, Smith DGE, Gally DL: Lymphoid follicle-dense mucosa at the terminal rectum is the principal site of colonization of enterohemorrhagic Escherichia coli 0157: H7 in the bovine host. Infect Immun 2003, 71:1505-1512.

17. Davis MA, Rice DH, Sheng H, Hancock DD, Besser TE, Cobbold R, Hovde CJ: Comparison of cultures from rectoanal-junction mucosal swabs and feces for detection of Escherichia coli 0157 in dairy heifers. Appl Environ Microbiol 2006, 72:3766-3770.

18. Lim JY, Li J, Sheng H, Besser TE, Potter K, Hovde CJ: Escherichia coli O157: $\mathrm{H} 7$ colonization at the rectoanal junction of long-duration culturepositive cattle. Appl Environ Microbiol 2007, 73:1380-1382.

19. Carlson BA, Nightingale KK, Mason GL, Ruby JR, Choat WT, Loneragan GH, Smith GC, Sofos JN, Belk KE: Escherichia coli O157:H7 strains that persist in feedlot cattle are genetically related and demonstrate an enhanced ability to adhere to intestinal epithelial cells. Appl Environ Microbiol 2009, 75:5927-5937.

20. Gyles CL: Shiga toxin-producing Escherichia coli: an overview. J Anim Sci 2007, 85:E45-62.

21. Woerner DR, Ransom JR, Sofos JN, Dewell GA, Smith GC, Salman MD, Belk KE: Determining the prevalence of Escherichia coli 0157 in cattle and beef from the feedlot to the cooler. J Food Prot 2006, 69:2824-2827.

22. Low JC, McKendrick LJ, McKechnie C, Fenlon D, Naylor SW, Currie C, Smith DGE, Allison L, Galy DL: Rectal carriage of enterohemorrhagic Escherichia coli 0157 in slaughtered cattle. Appl Environ Microbiol 2005, 71:93-97.

23. Geue L, Segura-Alvarez M, Conraths FJ, Kuczius T, Bockemuhl J, Karch H, Gallien P: A long-term study on the prevalence of Shiga toxin-producing Escherichia coli (STEC) on four German cattle farms. Epidemiol Infect 2002, 129:173-185.

24. LeJeune JT, Hancock D, Wasteson Y, Skjerve E, Urdahl AM: Comparison of E. coli 0157 and Shiga toxin-encoding genes (stx) prevalence between Ohio, USA and Norwegian dairy cattle. Int J Food Microbiol 2006, 109:19-24.

25. Chase-Topping ME, McKendrick IJ, Pearce MC, MacDonald P, Matthews L, Halliday J, Allison L, Fenlon D, Low JC, Gunn G, Woolhouse MEJ: Risk factors for the presence of high-level shedders of Escherichia coli 0157 on Scottish farms. J Clin Microbiol 2007, 45:1594-1603.

26. Zschöck M, Hamann HP, Kloppert B, Wolter W: Shiga-toxin-producing Escherichia coli in faeces of healthy dairy cows, sheep and goats: prevalence and virulence properties. Lett Appl Microbiol 2000, 31:203-208.

27. Wieler $L H$, Vieler E, Erpenstein C, Schlapp T, Steinruck H, Bauerfeind R, Byomi A, Baljer G: Shiga toxin-producing Escherichia coli strains from bovines: Association of adhesion with carriage of eae and other genes. Clin Microbiol 1996, 34:2980-2984

28. Schmidt H, Zhang WL, Hemmrich U, Jelacic S, Brunder W, Tarr PI, Dobrindt $\mathrm{U}$, Hacker J, Karch $\mathrm{H}$ : Identification and characterization of a novel genomic island integrated at selC in locus of enterocyte effacement-negative, Shiga toxin-producing Escherichia coli. Infect Immun 2001, 69:6863-6873.

29. Stevens MP, van Diemen PM, Frankel G, Phillips AD, Wallis TS: Efa1 influences colonization of the bovine intestine by Shiga toxin-producing Escherichia coli serotypes O5 and 0111. Infect Immun 2002, 70:5158-5166.

30. Karmali MA, Mascarenhas M, Shen SH, Ziebell K, Johnson S, Reid-Smith R, Isaac-Renton J, Clarks C, Rahn K, Kaper JB: Association of genomic O(-) island 122 of Escherichia coli EDL 933 with verocytotoxin-producing
Escherichia coli seropathotypes that are linked to epidemic and/or serious disease. J Clin Microbiol 2003, 41:4930-4940.

31. Nicholls $L$, Grant $T H$, Robins-Browne RM: Identification of a novel genetic locus that is required for in vitro adhesion of a clinical isolate of enterohaemorrhagic Escherichia coli to epithelial cells. Mol Microbiol 2000, 35:275-288.

32. Doughty S, Sloan J, Bennett-Wood V, Robertson M, Robins-Browne RM, Hartland EL: Identification of a novel fimbrial gene cluster related to long polar fimbriae in locus of enterocyte effacement-negative strains of enterohemorrhagic Escherichia coli. Infect Immun 2002, 70:6761-6769.

33. Bielaszewska M, Prager R, Vandivinit L, Musken A, Mellmann A, Holt NJ, Tarr PI, Karch H, Zhang W: Detection and characterization of the fimbrial sfp cluster in enterohemorrhagic Escherichia coli 0165:H25/NM isolates from humans and cattle. Appl Environ Microbiol 2009, 75:64-71.

34. Bülte M: Prevalence of verotoxinogenic Escherichia coli strains (VTEC) with special respect to the serovar 0157 in a herd of suckling cows. Arch Lebensmittelhyg 2004, 55:124-127.

35. Richter H, Klie H, Timm M, Gallien P, Steinruck H, Perlberg KW, Protz D: Verotoxin-producing $E$. coli (VTEC) in faeces from cattle slaughtered in Germany. Berl Munch Tierarztl Wochenschr 1997, 110:121-127.

36. Weber A, Klie H, Richter $H$, Gallien P, Timm M, Perlberg KW: Present problems in detection of sources of infection and chains of infection with enterohemorrhagic E. coli (EHEC). Berl Munch Tierarztl Wochenschr 1997, 110:211-213

37. Caprioli A, Tozzi AE: Epidemiology of Shiga toxin-producing Escherichia coli infections in continental Europe. Escherichia coli 0157:H7 and other Shiga toxin-producing E coli strains Washington, DC: American Society for MicrobiologyKaper JB, O'Brien AD 1998, 38-48.

38. Greenquist MA, Drouillard JS, Sargeant JM, Depenbusch BE, Shi XR, Lechtenberg KF, Nagaraja TG: Comparison of rectoanal mucosal swab cultures and fecal cultures for determining prevalence of Escherichia coli 0157: H7 in feedlot cattle. Appl Environ Microbiol 2005, 71:6431-6433.

39. Rice DH, Sheng HQQ, Wynia SA, Hovde CJ: Rectoanal mucosal swab culture is more sensitive than fecal culture and distinguishes Escherichia coli 0157: H7-colonized cattle and those transiently shedding the same organism. J Clin Microbiol 2003, 41:4924-4929.

40. Boerlin P, McEwen SA, Boerlin-Petzold F, Wilson JB, Johnson RP, Gyles CL: Associations between virulence factors of Shiga toxin-producing Escherichia coli and disease in humans. J Clin Microbiol 1999, 37:497-503.

41. Friedrich AW, Bielaszewska M, Zhang WL, Pulz M, Kuczius T, Ammon A, Karch H: Escherichia coli harboring shiga toxin 2 gene variants: frequency and association with clinical symptoms. Am J Infect Dis 2002, 185:74-84.

42. Mellmann A, Bielaszewska M, Kock R, Friedrich AW, Fruth A, Middendorf B, Harmsen D, Schmidt MA, Karch H: Analysis of collection of hemolytic uremic syndrome-associated enterohemorrhagic Escherichia coli. Emerg Infect Dis 2008, 14:1287-1290.

43. MicroBioNet: Serotypes of VTEC - the VTEC table. 2009 [http://www. microbionet.com.au/vtectable.htm].

44. Blanco M, Blanco JE, Blanco J, Gonzalez EA, Mora A, Prado C, Fernandez L, Rio M, Ramos J, Alonso MP: Prevalence and characteristics of Escherichia coli serotype 0157:H7 and other verotoxin-producing E. coli in healthy cattle. Epidemiol Infect 1996, 117:251-257.

45. Ogden ID, MacRae M, Strachan NJC: Is the prevalence and shedding concentrations of E. coli $\mathrm{O} 157$ in beef cattle in Scotland seasonal? FEMS Microbiol Lett 2004, 233:297-300.

46. Cobbold RN, Rice DH, Szymanski M, Call DR, Hancock DD: Comparison of shiga-toxigenic Escherichia coli prevalences among dairy, feedlot, and cow-calf herds in Washington State. Appl Environ Microbiol 2004, 70:4375-4378.

47. Mechie SC, Chapman PA, Siddons CA: A fifteen month study of Escherichia coli O157:H7 in a dairy herd. Epidemiol Infect 1997, 118:17-25.

48. Wieler LH, Sonjinski G, Schlapp T, Failing K, Weiss R, Menge C, Baljer G Longitudinal prevalence study of diarrheagenic Escherichia coli in dairy calves. Berl Munch Tierarztl Wochenschr 2007, 120:296-306.

49. Kemper N: Teilprojekt C: Tierhaltung: Tiergesundheit und Antibiotikarückstände in der Milchviehhaltung. Ergebnisse des Projektes "COMPASS" Kiel/GermanyTaube F, Kelm M, Verreet J-A 2007, 62-66.

50. Cannon RM, Roe RT: Livestock Disease Surveys: A Field Manual for Veterinarians. Australian Government Publishing Service, Canberra 1982, 35.

51. Edmonson AJ, Lean IJ, Weaver LD, Farver T, Webster G: A body condition scoring chart for holstein dairy cows. J Dairy Sci 1989, 72:68-78. 
52. Karch $H$, Meyer $\mathrm{T}$ : Single primer pair for amplifying segments of distinct Shiga-like-toxin genes by Polymerase Chain-Reaction. J Clin Microbiol 1989, 27:2751-2757.

53. Cebula TA, Payne WL, Feng P: Simultaneous identification of strains of Escherichia coli serotype 0157:H7 and their Shiga-like toxin type by mismatch amplification mutation assay-multiplex PCR. J Clin Microbiol 1995, 33:1048-1048.

54. Schmidt $H$, Karch $H$, Beutin L: The large-sized plasmids of enterohemorrhagic Escherichia coli 0157 strains encode hemolysins which are presumably members of the Escherichia coli alpha-hemolysin family. FEMS Microbiol Lett 1994, 117:189-196.

55. Schmidt H, Plaschke B, Franke S, Russmann H, Schwarzkopf A, Heesemann J, Karch H: Differentiation in virulence patterns of Escherichia coli possessing eae genes. Med Microbiol Immunol 1994, 183:23-31.

56. Wieler LH, Tigges M, Ebel F, Schaferkordt S, Djafari S, Schlapp T, Baljer G, Chakraborty T: The enterohemolysin phenotype of bovine Shiga-like toxin-producing Escherichia coli (SLTEC) is encoded by the EHEChemolysin gene. Vet Microbiol 1996, 52:153-164

57. Ørskov F, Ørskov I: Serotyping of Escherichia coli. Meth Microbiol 1984, 14:43-112.

doi:10.1186/1757-4749-2-7

Cite this article as: Menrath et al:: Shiga toxin producing Escherichia coli: identification of non-O157:H7-Super-Shedding cows and related risk factors. Gut Pathogens 2010 2:7.

\section{Submit your next manuscript to BioMed Central and take full advantage of:}

- Convenient online submission

- Thorough peer review

- No space constraints or color figure charges

- Immediate publication on acceptance

- Inclusion in PubMed, CAS, Scopus and Google Scholar

- Research which is freely available for redistribution

Submit your manuscript at www.biomedcentral.com/submit 